\title{
INFORMACION
}

\section{El centenario de López Portillo}

T A Academia Mexicana Correspondiente de la Real Española, la Universidad Nacional de México y la Sociedad Mexicana de Geografía y Estadística han conmemorado, conjuntamente, el primer centenario del natalicio de don José López Portillo y Rojas, miembro muy distinguido de las tres corporaciones y uno de los hombres que honraron a nuestras letras, en las postrimerías del siglo xIx y en los primeros años del actual. Desde luego, perteneció a esa generación de novelistas que continuó reflejando el ambiente mexicano y el alma de sus habitantes, con un decoro y una prestancia que dan interés al realismo en nuestra literatura, como lo dieron en la castellana José María de Pereda, Juan Valera, doña Emilia Pardo Bazán y don Benito Pérez Galdós.

Nació en Guadalajara tan ilustre varón, el día 26 de mayo de 1850. Fué hijo del jurisconsulto don Jesús López Portillo, andando el tiempo decano del foro jalisciense, y de doña María Rojas. De niño vióse privado de la atención directa de sus padres, pues don Jesús sufrió destierro por orden de don Antonio López de Santa Anna. A los doce años publica el periódico estudiantil La Exhalación. Quiere dedicarse al estudio de la medicina, ya en plena juventud, y viene a la ciudad de México, donde cambia la primera de esas carreras, por la de jurisprudencia, que termina en la ciudad de Guadalajara. Es la época de la lucha entre el Imperio y la República.

Viaja por Europa, ya con el título de abogado. Pasa por los Estados Unidos y recorre Irlanda, Escocia e Inglaterra; hace su 
visita obligada a Francia, llega a Italia y se dirige al Oriente. Egipto y Palestina eran metas de un viaje, alucinado como todos los que se emprenden a los veintidós años. Hace constar que es el primer mexicano que ha cruzado el Canal de Suez. A su regreso publica su libro Impresiones de viaje.

Regresa a Guadalajara y se dedica al ejercicio de su profesión. Pasa a México y se incorpora a la Facultad de Jurisprudencia, para enseñar Derecho. En el telar se teje ya la más famosa de sus novelas: La parcela. Como todos los hombres de letras de su época, sigue uno de los dos caminos que dan para vivir: la política. El de la diplomacia ha de ser recorrido por él más tarde, aunque muy fugazmente. Es diputado lerdista en la legislatura que actúa en el bienio 1875-77. Al triunfo del porfirismo, se retira a su tierra natía, para ejercer el periodismo y ser diputado nuevamente en 1880 . Funda y dirige la revista La República Literaria. De lleno en la política, vuelve a ser diputado, ahora por Nuevo León. Se incorpora al grupo científico y hace su aparición en la diplomacia, como delegado a la Primera Conferencia Panamericana, que se reúne en México a fines de 1901. Su incorporación al movimiento reyista, lo hizo caer en desgracia con el general Díaz. Se le abrió un proceso, después de haber sido desaforado como senador. Se le desprestigió como funcionario y como caballero. El triunfo de la Revolución maderista lo reivindica. El presidente De la Barra lo hace su Ministro de Educación. Popularmente resulta electo gobernador del Estado de Jalisco. Tiene la desgracia de aceptar la Secretaría de Relaciones Exteriores, en uno de los gabinetes del presidente Victoriano Huerta. Sufre, a la caída del dictador, graves persecuciones.

A partir de 1916 radica en México, dedicado a su profesión y al periodismo. En ese mismo año la Academia Mexicana lo había hecho su Director. En 1922 fué designado profesor de Derecho Internacional Público en la Escuela de Jurisprudencia. Falleció el 22 de mayo de 1923. Legó a México una vasta obra incorporada a los diarios y revistas en los que colaboró durante toda su vida. Fue novelista, con La parcela, Fuertes y débiles y Los precursores. Escribió cuentos de sabor netamente mexicano que se incorporaron a sus libros: Novelas cortas, Historias, historietas y cuentecillos; 
practicó la historia en su obra Elevación y caida de Porfirio Diaz, y la biografía literaria, con Rosario la de Acuña. Cultivó la poesía en su juventud: Armonias fugitivas, y en toda su vida, contra lo que dijeron sus enemigos, fue "un amante de la justicia" y como buen mexicano deseaba ver a su patria "fuerte, grande y victoriosa". 
